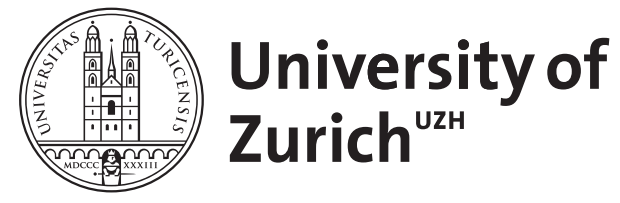

\title{
Hippocampal atrophy in subcortical vascular dementia
}

\author{
van de Pol, L ; Gertz, H J ; Scheltens, P ; Wolf, H
}

\begin{abstract}
Patient groups with $\mathrm{AD}$ and $\mathrm{SVaD}$ as identified by current research criteria appear to overlap considerably with regard to the feature of Hc atrophy. While contamination with AD is a likely cause, other mechanisms of Hc atrophy in SVaD also deserve consideration. The findings have implications for the design of future clinical trials of SVaD.
\end{abstract}

DOI: https://doi.org/10.1159/000326695

Posted at the Zurich Open Repository and Archive, University of Zurich ZORA URL: https://doi.org/10.5167/uzh-49614

Journal Article

Published Version

Originally published at:

van de Pol, L; Gertz, H J; Scheltens, P; Wolf, H (2011). Hippocampal atrophy in subcortical vascular dementia. Neurodegenerative Diseases, 8(6):465-469.

DOI: https://doi.org/10.1159/000326695 


\title{
Hippocampal Atrophy in Subcortical Vascular Dementia
}

\author{
Laura van de Pol ${ }^{a}$ Hermann-Josef Gertz ${ }^{b}$ Philip Scheltens ${ }^{a}$ Henrike Wolf ${ }^{b, c}$ \\ aDepartment of Neurology and Alzheimer Center, VU University Medical Center Amsterdam, Amsterdam, \\ The Netherlands; ${ }^{b}$ Department of Psychiatry, University of Leipzig, Memory Clinic, Leipzig, Germany; \\ 'Department of Psychiatry Research and Geriatric Psychiatry, Psychiatric University Hospitals (PUK), \\ University of Zurich, Zurich, Switzerland
}

\section{Key Words}

Hippocampal atrophy $\cdot$ Vascular dementia, subcortical

\begin{abstract}
Background and Purpose: New research criteria for subcortical vascular dementia (SVaD) have been suggested to define a more homogeneous subgroup of vascular dementia. Hippocampal $(\mathrm{Hc})$ atrophy is a hallmark of Alzheimer's disease (AD), but it also occurs in other dementia disorders including vascular dementias. So far, it is unknown to which extent $\mathrm{Hc}$ atrophy is present in SVaD. Methods: From a larger consecutive referral population in a memory clinic, 11 patients fulfilling the research criteria for SVaD were carefully matched with comparison groups of healthy controls and patients with AD. To estimate the extent of Hc atrophy in $\mathrm{SVaD}$, both Hc volumetry and visual rating of medial temporal lobe atrophy (MTA) were applied. Results: In SVaD, significant $\mathrm{Hc}$ atrophy occurred. The extent was intermediate between controls and patients with AD both on Hc volumetry and visual MTA ratings. At the same level of global cognition, $\mathrm{Hc}$ volumes were reduced by $11.6 \%$ in $\mathrm{SVaD}$ and $16.6 \%$ in $A D$, relative to controls. Conclusions: Patient groups with $A D$ and $S V a D$ as identified by current research criteria appear to overlap considerably with regard to the feature of $\mathrm{Hc}$ at-
\end{abstract}

rophy. While contamination with $A D$ is a likely cause, other mechanisms of $\mathrm{Hc}$ atrophy in SVaD also deserve consideration. The findings have implications for the design of future clinical trials of SVaD.

Copyright $\odot 2011$ S. Karger AG, Basel

\section{Introduction}

Vascular dementia is a broad term encompassing heterogeneous clinical and pathological syndromes [1]. Recognizing the need for well-defined and homogeneous subtypes of vascular dementia, new research criteria have been proposed for subcortical vascular dementia (SVaD) [2], which is presumed to be the most common type of vascular dementia. These criteria emphasize small vessel disease as the chief vascular etiology, lacunar infarcts and ischemic white matter lesions as the primary type of brain lesions, subcortical location as the primary location of the lesions, and the subcortical clinical syndrome as the primary clinical manifestation [2]. The new criteria are expected to lead to a more predictable clinical presentation, natural history, outcome and treatment responses [2].

\section{KARGER \\ Fax +4161306 1234 \\ E-Mail karger@karger.ch}

www.karger.com
(C) 2011 S. Karger AG, Basel

1660-2854/11/0086-0465\$38.00/0

Accessible online at:

www.karger.com/ndd
PD Dr. med. Henrike Wolf

Department of Psychiatry Research and Geriatric Psychiatry University of Zurich, Psychiatric University Hospitals (PUK) GPZ, Minervastrasse 145, CH-8008 Zurich (Switzerland)

Tel.+41 44389 1480,E-Mail henrike.wolf@bli.uzh.ch 
Hippocampal $(\mathrm{Hc})$ atrophy frequently occurs in Alzheimer's disease (AD) [3-6], but also in other dementia disorders [7-9]. A number of previous studies reported evidence of significant Hc atrophy in vascular dementia [7, 9-14], and one recent study stressed the relevance of Hc atrophy regarding treatment responses in a randomized trial [15]. However, these findings have been based on heterogeneous definitions of vascular dementia and often included patients with cortical lesions. So far, it remains unclear to which extent Hc atrophy is present in SVaD.

In this study, we therefore investigated Hc atrophy on $\mathrm{MRI}$ in SvaD in comparison to $\mathrm{AD}$ and healthy control subjects. We used both Hc volumetry and visual ratings of medial temporal lobe atrophy (MTA) [5].

\section{Methods}

\section{Subjects and Pair-Matching Procedure}

The subjects were recruited from all patients and controls seen at the Free University Medical Center (VUMC) Amsterdam between January 2000 and June 2003. The new SVaD criteria [2] were operationalized in the following way: all patients had to have both (a) objective impairment of memory and executive functions (cognitive phenotype of SVaD) and (b) extending periventricular and deep white matter lesions on brain MRI (radiological phenotype of SVaD). Patients with cortical infarcts were excluded. Of all patients seen at the VUMC, 11 met these criteria for SVaD [2].

In the same time period (January 2000 to December 2003), 77 patients were diagnosed with AD according to the NINCDS research criteria and published diagnostic procedures [5]. Of those, 11 patients were selected who optimally matched the SVaD patients in age, gender and severity of cognitive impairment. Recorded results from the Mini-Mental State Examination (MMSE) [16] and the global score of the Clinical Dementia Rating (CDR) scale [17] were used to match the disease groups for severity of cognitive impairment.

Thirty-one healthy control subjects were recruited through advertisements and among spouses and friends of demented patients. They did not report any cognitive complaints. Eleven controls matching the vascular dementia patients in age and gender were chosen.

\section{Clinical and Neuropsychological Instruments}

The MMSE [16] and CDR scale [17] belong to a set of standard batteries routinely used at the VUMC. The CDR was based on information from both patients and a collateral source, and was determined according to published rules [17].

\section{MRI Acquisition}

MRI was conducted with a 1.0-tesla tomograph (Siemens Magnetom Impact Expert, Erlangen, Germany) using a magnetization-prepared rapid gradient echo (MPRAGE) and a fluid-attenuated inversion recovery (FLAIR) sequence with the following characteristics: (1) MPRAGE - coronal, TR $=15 \mathrm{~ms}, \mathrm{TE}=7 \mathrm{~ms}$,
$\mathrm{TI}=300 \mathrm{~ms}$, matrix $256 \times 256$, pixel dimensions $0.98 \times 0.98$ $\mathrm{mm}$, slice thickness $1.49 \mathrm{~mm}$; (2) FLAIR - axial, TR $=9,000 \mathrm{~ms}$, $\mathrm{TE}=105 \mathrm{~ms}, \mathrm{TI}=2,200 \mathrm{~ms}$, matrix $256 \times 256 \times 17$, pixel dimensions $0.98 \times 0.98 \mathrm{~mm}$, slice thickness $5.0 \mathrm{~mm}$.

\section{Hc Volumetry and Visual Ratings}

To examine the occurrence and extent of Hc atrophy, both visual and volumetric assessments were performed. Both raters (L.v.d.P. and A. Hensel) were blinded to diagnosis, age and identity of the patients as well as each other's rating results.

All visual assessments were performed by L.v.d.P. Hc atrophy was visually assessed by the MTA rating scale [5]. MTA was rated on coronal MPRAGE images separately for each hemisphere. For the purpose of this study, the maximum score for either hemisphere was recorded. In addition, age-related white matter changes (ARWMC) were rated on the axial FLAIR images using the ARWMC scale [18]. Ten scans were rated twice (by L.v.d.P.) to assess intrarater reliability. The $\kappa$ values were 0.7 for the MTA rating and 0.8 for the ARWMC rating.

Hc volumetry was performed by A. Hensel on the MPRAGE images using the BRIAN software package. Volumetric datasets were transferred to a UNIX system and processed as previously described [19]. Six cross-sections of the hippocampus were segmented manually in the coronal plane on both hemispheres. The left and right Hc volumes were summed to yield the total Hc volume.

All patients and controls provided written informed consent for their clinical data to be used for research. The study received ethical approval by the local ethics committee at the VU University Amsterdam.

\section{Statistical Analyses}

All statistical computations were performed using SPSS for Windows (version 12.0.0). The significance level was set to be 0.05 for all analyses. Group differences in Hc volumes as well as MTA and ARWMC scores were assessed by the Kruskal-Wallis H test, followed by groupwise comparison by Mann-Whitney U tests.

\section{Results}

The sample characteristics are summarized in table 1 . Controls and disease groups were accurately matched regarding age and gender. Concerning severity of cognitive impairment and duration of symptoms, the disease groups compared well. In accordance with the diagnoses, white matter changes were significantly more pronounced in SVaD patients than in AD patients and controls.

$\mathrm{Hc}$ volumes were significantly reduced in both $\mathrm{SVaD}$ and $\mathrm{AD}$ - by 11.6 and $16.6 \%$, respectively - as compared with controls (Kruskal-Wallis test; $\mathrm{p}=0.002$ ). Hc volumes in SVaD were intermediate and differed significantly from $\mathrm{AD}(\mathrm{p}=0.001)$ and controls $(\mathrm{p}=0.015)$ (fig. 1$)$. The MTA ratings confirmed this pattern (table 2). The MTA scores differed significantly between the three 
Table 1. Description of the sample

\begin{tabular}{llll}
\hline & SVaD & AD & Control \\
\hline Number $^{1}$ & $11(4)$ & $11(4)$ & $11(4)$ \\
Age, years & $67 \pm 8$ & $69 \pm 8$ & $68 \pm 8$ \\
$\begin{array}{l}\text { MMSE score } \\
\quad \text { Mean } \pm \text { SD }\end{array}$ & $22 \pm 3$ & $22 \pm 3$ & $28 \pm 2$ \\
$\quad$ Range & $16-27$ & $17-26$ & $24-30$ \\
CDR score, n & & & \\
$\quad 0.5$ & 3 & 4 & 0 \\
$\quad 1 \quad$ & 5 & 0 \\
$\quad 2$ & 0 & 2 & 0 \\
Symptom duration, years & $3 \pm 2$ & $4 \pm 3$ & 0 \\
Hc volume left + right, $\mathrm{cm}^{3}$ & $3.20 \pm 0.32$ & $3.02 \pm 0.34$ & $3.62 \pm 0.37$ \\
ARWMC rating & & & \\
$\quad$ Median & 17 & 1 & 4 \\
$\quad$ Range & $7-21$ & $0-6$ & $5-20$ \\
\hline
\end{tabular}

Values are means \pm SD unless specified otherwise. In 3 cases (2 SVaD, 1 control), the MMSE score was missing.

${ }^{1}$ Values in parentheses denote numbers of females.

groups (Kruskal-Wallis test; $\mathrm{p}=0.001$ ), and MTA rating scores in $\mathrm{SVaD}$ were intermediate between controls and $\mathrm{AD}$ patients, with significant differences between $\mathrm{SVaD}$ and controls $(\mathrm{p}=0.002)$ as well as between SVaD and AD $(\mathrm{p}=0.001)$. Nine $\mathrm{SVaD}$ as well as $9 \mathrm{AD}$ patients, but only 2 controls, had MTA scores of 2 or greater. Moderate (score 3) and severe atrophy (score 4) tended to be more common in patients with AD compared with SVaD (7 vs. 4$)$.

\section{Discussion}

To our knowledge, this is the first study to quantify Hc atrophy in stringently defined $\mathrm{SVaD}$ in comparison to $\mathrm{AD}$ and healthy controls. In contrast to other studies using heterogeneous definitions of vascular dementia, the disease groups were accurately matched for level of global cognitive impairment, age and gender.

Subjects with SVaD had significant Hc atrophy, evident by both Hc volumetry and visual rating of MTA scores as compared with controls. While MTA and Hc volume reductions in $\mathrm{SVaD}$ occurred with a comparable frequency to $\mathrm{AD}, \mathrm{Hc}$ atrophy was significantly less severe than in AD. These findings are comparable with a number of previous studies showing that Hc atrophy commonly occurs in vascular dementia $[7,9-13]$ and might
Table 2. MTA ratings

\begin{tabular}{llll}
\hline & \multicolumn{3}{l}{ Number of subjects } \\
\cline { 2 - 4 } & control & SVaD & AD \\
\hline MTA score & & & \\
0 (no atrophy) & 3 & 0 & 0 \\
1 & 6 & 2 & 2 \\
2 & 2 & 5 & 2 \\
3 & 0 & 3 & 6 \\
4 (most severe atrophy) & 0 & 1 & 1 \\
\hline
\end{tabular}

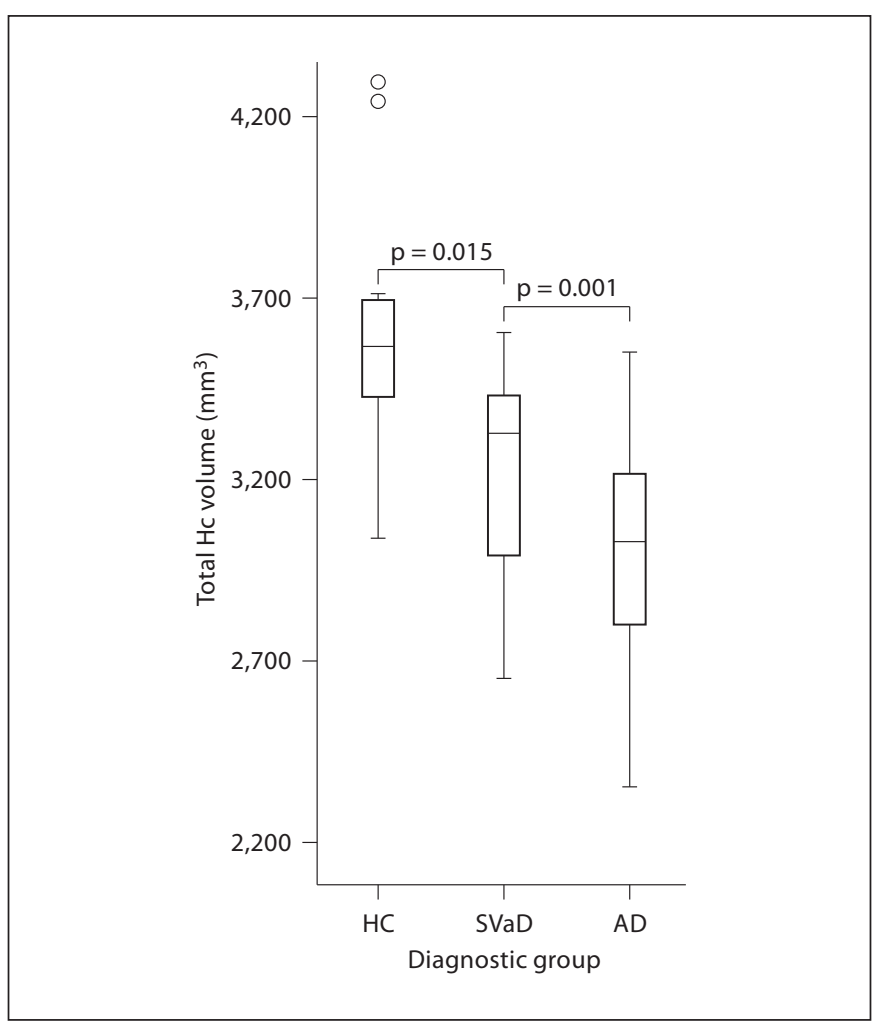

Fig. 1. Boxplot of total Hc volume estimate in patients with SVaD and $\mathrm{AD}$ and in healthy controls $(\mathrm{HC} ; \mathrm{n}=33)$. Boxes: interquartile range. Lines in boxes: medians. Outliers are displayed individually.

be milder than in $\mathrm{AD}[7,9,11]$. However, none of these studies strictly focused on SVaD.

The mechanisms of Hc atrophy in SVaD remain unclear and could be heterogeneous. One possible explanation for our findings is that cooccurrent Alzheimer pathology, particularly neurofibrillary tangles (NFT), may have contributed to the Hc atrophy seen in SVaD. Close 
correlations have been shown between Hc neuronal loss, NFT and Hc atrophy in cases with AD [20], and even across different dementia disorders [10].

However, Hc atrophy in SVaD has been shown to occur in the absence of AD pathology. In postmortem studies, up to $50 \%$ of cases with SVaD were found to have Braak stages of 0/I, i.e. negligible NFT pathology [20-22]. Yet, there was significant Hc pyramidal cell loss in some of these cases [21]. The most important findings in support of 'pure' vascular mechanisms of Hc atrophy derive from cases with CADASIL (cerebral autosomal dominant arteriopathy with subcortical infarcts and leukoencephalopathy). These patients often have pronounced Hc atrophy correlating with their global cognitive state, but because they are aged $<60$ years, comorbid Alzheimer pathology is unlikely [23].

In a large histopathological case series of ischemic vascular dementia, some manner of Hc injury was commonly found and the substrates were noted to be extremely variable, ranging from regions with cystic encephalomalacia to well-defined regions with segmental Hc scarring, resembling Hc sclerosis [22].

In our sample, patients with SVaD had significantly less Hc atrophy despite the same degree of global cognitive disturbances as AD patients (MMSE score 22), but the quantitative difference was small (5\%). Larger studies on vascular dementia add plausibility to this finding by showing that Hc atrophy is the major correlate of global cognition in vascular dementia, whereas white matter lesions contribute more specifically to executive dysfunction [24]. Beyond easily detectable radiological phenomena of white matter lesions and Hc atrophy, the cholinergic denervation caused by ischemic damage to fiber tracts appears to be of specific pathophysiological relevance in SVaD [25]. Differing pathophysiological mechanisms (neurodegenerative vs. microvascular) could result in shape and texture differences, possibly leading to small but significant differences in Hc volume between $\mathrm{AD}$ and $\mathrm{SVaD}$. This needs to be addressed in future imaging studies.

Some limitations of our study have to be mentioned. The sample size was small, but the design was optimized to create homogeneous groups and to avoid the use of statistical corrections. It remains unclear whether the volumetric estimations from our study can be generalized. The Hc volume loss in the AD group was rather small compared with other studies, some of which used the same protocol $[19,26]$. This could be due to the relatively young age, mild disease severity or chance. A smaller than expected $\mathrm{Hc}$ volume loss in $\mathrm{AD}$ decreases the power to detect a true group difference, and hence also the likelihood of a type I error.

In conclusion, patient groups with $\mathrm{AD}$ and $\mathrm{SVaD}$ as identified by current research criteria appear to overlap considerably with regard to the feature of Hc atrophy. While contamination with $\mathrm{AD}$ is a likely cause, other mechanisms of $\mathrm{Hc}$ atrophy in $\mathrm{SVaD}$ also deserve consideration. In future trials of SVaD, the degree of $\mathrm{Hc}$ atrophy should be taken into account in addition to the defining features.

\section{Acknowledgments}

This study was supported by the Interdisziplinäre Zentrum für Klinische Forschung (IZKF) at the University of Leipzig (Projekt C8) as well as the Alzheimer Forschung Initiative (AFI) and the Internationale Stichting Alzheimer Onderzoek (ISAO). The authors would like to thank Dr. Anke Hensel, formerly at the Memory Clinic Leipzig, for her highly valued contribution to this project.

\section{References}

1 Román GC, Tatemichi TK, Erkinjuntti T, Cummings JL, Masdeu JC, Garcia JH, Amaducci L, Orgogozo JM, Brun A, Hofman A, et al: Vascular dementia: diagnostic criteria for research studies. Report of the NINDSAIREN International Workshop. Neurology 1993;43:250-260.

2 Erkinjuntti T, Inzitari D, Pantoni L, Wallin A, Scheltens P, Rockwood K, Roman GC, Chui H, Desmond DW: Research criteria for subcortical vascular dementia in clinical trials. J Neural Transm Suppl 2000;59:23-30.
3 George AE, de Leon MJ, Stylopoulos LA, Miller J, Kluger A, Smith G, Miller DC: CT diagnostic features of Alzheimer disease: importance of the choroidal/hippocampal fissure complex. AJNR Am J Neuroradiol 1990;11:101-107.

4 Jobst KA, Smith AD, Szatmari M, Molyneux A, Esiri ME, King E, Smith A, Jaskowski A, McDonald B, Wald N: Detection in life of confirmed Alzheimer's disease using a simple measurement of medial temporal lobe atrophy by computed tomography. Lancet 1992;340:1179-1183.
5 Scheltens P, Leys D, Barkhof F, Huglo D, Weinstein HC, Vermersch P, Kuiper M, Steinling M, Wolters EC, Valk J: Atrophy of medial temporal lobes on MRI in 'probable' Alzheimer's disease and normal ageing: diagnostic value and neuropsychological correlates. J Neurol Neurosurg Psychiatry 1992; 55:967-972.

6 Seab JP, Jagust WJ, Wong ST, Roos MS, Reed BR, Budinger TF: Quantitative NMR measurements of hippocampal atrophy in Alzheimer's disease. Magn Reson Med 1988;8: 200-208. 
7 Barber R, Ballard C, McKeith IG, Gholkar A, O'Brien JT: MRI volumetric study of dementia with Lewy bodies: a comparison with $\mathrm{AD}$ and vascular dementia. Neurology 2000;54: 1304-1309.

8 Barkhof F, Polvikoski TM, van Straaten ECW, Kalaria RN, Sulkava R, Aronen HJ, Niinistö L, Rastas S, Oinas M, Scheltens P, Erkinjuntti T: The significance of medial temporal lobe atrophy: a postmortem MRI study in the very old. Neurology 2007;69: 1521-1527.

9 Laakso MP, Partanen K, Riekkinen P, Lehtovirta M, Helkala EL, Hallikainen M, Hanninen T, Vainio P, Soininen H: Hippocampal volumes in Alzheimer's disease, Parkinson's disease with and without dementia, and in vascular dementia: an MRI study. Neurology 1996;46:678-681.

10 Burton EJ, Barber R, Mukaetova-Ladinska EB, Robson J, Perry RH, Jaros E, Kalaria RN, O'Brien JT: Medial temporal lobe atrophy on MRI differentiates Alzheimer's disease from dementia with Lewy bodies and vascular cognitive impairment: a prospective study with pathological verification of diagnosis. Brain 2009;46:195-203.

11 Du AT, Schuff N, Laakso MP, Zhu XP, Jagust WJ, Yaffe K, Kramer JH, Miller BL, Reed BR, Norman D, Chui HC, Weiner MW: Effects of subcortical ischemic vascular dementia and $\mathrm{AD}$ on entorhinal cortex and hippocampus. Neurology 2002;58:1635-1641.

12 Fein G, di Sclafani V, Tanabe J, Cardenas V, Weiner MW, Jagust WJ, Reed BR, Norman D, Schuff N, Kusdra L, Greenfield T, Chui H: Hippocampal and cortical atrophy predict dementia in subcortical ischemic vascular disease. Neurology 2000;55:1626-1635.
13 Gainotti G, Acciarri A, Bizzarro A, Marra C, Masullo C, Misciagna S, Tartaglione T, Valenza A, Colosimo C: The role of brain infarcts and hippocampal atrophy in subcortical ischaemic vascular dementia. Neurol Sci 2004;25:192-197.

14 Hanyu H, Asano T, Iwamoto T, Takasaki M, Shindo $\mathrm{H}$, Abe K: Magnetization transfer measurements of the hippocampus in patients with Alzheimer's disease, vascular dementia, and other types of dementia. AJNR Am J Neuroradiol 2000;21:1235-1242.

15 Román GC, Salloway S, Black SE, Royall DR, DeCarli C, Weiner MW, Moline M, Kumar D, Schindler R, Posner H: Randomized, placebo-controlled, clinical trial of donepezil in vascular dementia: differential effects by hippocampal size. Stroke 2010;41:12131221.

16 Folstein MF, Folstein SE, McHugh PR: 'Mini-Mental State': a practical method for grading the cognitive state of patients for the clinician. J Psychiatr Res 1975;12:189-198.

17 Hughes CP, Berg L, Danziger WL, Coben LA, Martin RL: A new clinical scale for the staging of dementia. Br J Psychiatry 1982; 140:566-572.

18 Wahlund LO, Barkhof F, Fazekas F, Bronge L, Augustin M, Sjögren M, Wallin A, Ader H, Leys D, Pantoni L, Pasquier F, Erkinjuntti T, Scheltens P, European Task Force on AgeRelated White Matter Changes: A new rating scale for age-related white matter changes applicable to MRI and CT. Stroke 2001;32: 1318-1322.

19 Wolf H, Grunwald M, Kruggel F, RiedelHeller SG, Angerhöfer S, Hojjatoleslami A, Hensel A, Arendt T, Gertz H: Hippocampal volume discriminates between normal cognition, questionable and mild dementia in the elderly. Neurobiol Aging 2001;22:177186.
20 Zarow C, Vinters HV, Ellis WG, Weiner MW, Mungas D, White L, Chui HC: Correlates of hippocampal neuron number in Alzheimer's disease and ischemic vascular dementia. Ann Neurol 2005;57:896-903.

21 Kril JJ, Patel S, Harding AJ, Halliday GM: Patients with vascular dementia due to microvascular pathology have significant hippocampal neuronal loss. J Neurol Neurosurg Psychiatry 2002;72:747-751.

22 Vinters HV, Ellis WG, Zarow C, Zaias BW, Jagust WJ, Mack WJ, Chui HC: Neuropathologic substrates of ischemic vascular dementia. J Neuropathol Exp Neurol 2000;59:931945.

23 O'Sullivan M, Ngo E, Viswanathan A, Jouvent E, Gschwendtner A, Saemann PG, Duering $\mathrm{M}$, Pachai $\mathrm{C}$, Bousser $\mathrm{MG}$, Chabriat $\mathrm{H}$, Dichgans M: Hippocampal volume is an independent predictor of cognitive performance in CADASIL. Neurobiol Aging 2009; 30:890-897.

24 Bastos-Leite AJ, van der Flier WM, van Straaten ECW, Staekenborg SS, Scheltens P, Barkhof F: The contribution of medial temporal lobe atrophy and vascular pathology to cognitive impairment in vascular dementia. Stroke 2007;38:3182-3185.

25 Mesulam M, Siddique T, Cohen B: Cholinergic denervation in a pure multi-infarct state: observations on CADASIL. Neurology 2003; 60:1183-1185.

26 Wolf H, Hensel A, Kruggel F, Riedel-Heller SG, Arendt T, Wahlund LO, Gertz HJ: Structural correlates of mild cognitive impairment. Neurobiol Aging 2004;25:913-924. 